\title{
DETERMINAÇÃO DE UMIDADE, FIBRAS, LIPÍDIOS, CINZAS E SÍLICA EM PLANTAS MEDICINAIS
}

\author{
MARIA MOZARINA BESERRA ALMEIDA* \\ MARIA DE FÁTIMA G. LOPES* \\ PAULO HENRIQUE MACHADO DE SOUSA** \\ CÉLIA MARIA D. NOGUEIRA* \\ CARLOS EMANUEL DE CARVALHO MAGALHÃES***
}

\begin{abstract}
Considerando a importância do estudo das plantas medicinais foram realizadas análises físico-químicas de folhas de dez amostras de Alecrim-pimenta (Lippia sidoides Cham.), Alfavaca (Ocimum gratissimum L.), Cajá-umbu (Spondias aff. tuberosa), Eucalipto (Eucalyptus tereticornis Smith), Goiabeira (Psidium guajava L.), Maracujá (Passiflora edulis Sims.), Mostarda (Brassica integrigolia O. E. Schulz), Quebra-pedra (Phyllanthus amorus Schum. Et Thorn.), Sabugueiro (Sambucus australis Cham. \& Schlecht.) e Torém (Cecropia sp.). Constatou-se pouca discrepância entre os teores de cinzas totais e fibra bruta dos vegetais estudados. Apenas a Alfavaca e o Maracujá destacaramse pelas maiores concentrações de cinzas totais, evidenciando a riqueza dessas amostras em elementos minerais. Com relação à fibra bruta deve-se salientar os elevados teores encontrados para Quebra-pedra e Torém, sugerindo-se estudos para utilização dessas plantas como fonte alternativa de fibra na dieta alimentar. Verificou-se sensível variação nos resultados da determinação da gordura, destacando-se os menores percentuais para Alecrim-pimenta e Goiabeira, importante fator a considerar quando ao uso medicinal desses vegetais.
\end{abstract}

PALAVRAS-CHAVE: PLANTAS MEDICINAIS; ALIMENTOS FUNCIONAIS.

* $\quad$ Professores, Universidade Federal do Ceará (UFC), Departamento de Química Analítica e Físico-química, Fortaleza, CE (e-mail: mozaba@ufc.br).

** Bolsista de Extensão Tecnológica, Fundação Cearense de Apoio ao Desenvolvimento Científico e Tecnológico (FUNCAP), UFC, Fortaleza, CE (e-mail: phmachado@uol.com.br).

Professor, Universidade Estadual do Ceará (UECE), Departamento de Física e Química, Fortaleza, CE (e-mail: cemagal@ufc.br). 


\section{INTRODUÇÃO}

O hábito de recorrer às virtudes curativas de certos vegetais constitui uma das primeiras manifestações do esforço humano para compreender e utilizar a natureza. Estudos de Arqueologia demonstram que há mais de 3.000 anos os vegetais são utilizados como alimentos, medicamentos ou cosméticos (BROSSE, 1990).

O conhecimento empírico acumulado sobre as plantas medicinais ainda representa o único recurso terapêutico de muitas comunidades e grupos étnicos. Essa prática, que se caracteriza pela utilização dos recursos naturais como forma de tratamento e cura de doenças, é tão antiga quanto a espécie humana (DI STASI, 1996). De acordo com dados da Organização Mundial da Saúde, cerca de $80 \%$ da população mundial já recorreu aos benefícios de certas ervas com ação terapêutica popularmente reconhecida (MARTINS e SANTOS, 1995).

O Brasil é rico em vegetais e o uso de plantas medicinais como recurso terapêutico alternativo tem-se mostrado crescente devido ao seu baixo custo e facilidade de acesso, principalmente na região nordestina.

O teor de substâncias inorgânicas, resultantes da completa incineração de material de origem vegetal submetido à análise química, indica a riqueza da amostra em elementos minerais. Deve-se considerar o teor de sílica presente nas amostras (SILVA, 1990), pois ao serem calcinadas eliminam seus constituintes orgânicos, resultando apenas os constituintes inorgânicos e a sílica (NOGUEIRA et al., 1996).

As gorduras ou lipídios, substâncias insolúveis em água, desempenham importante papel na reparação das perdas materiais do organismo e para o suprimento de energia. As gorduras dificultam a digestão dos alimentos e, portanto, não devem ser ingeridas em excesso (HARPER, RODWELL e MAYES, 1982).

Fibras dietéticas são componentes das paredes vegetais que não são digeridos pelas enzimas do sistema digestivo do homem e cuja deficiência causa doenças. As fibras exercem diversas funções fisiológicas como a regulação da função intestinal, a prevenção de constipação, o melhoramento da flora bacteriana intestinal, a inibição 
da absorção de substâncias prejudiciais, a prevenção de câncer de cólon, a imunoativação, a regulação dos conteúdos de açúcar, gordura e colesterol no sangue e inúmeras outras funções (HASLER, 1998; WHEN..., 2000).

Considerando a importância do estudo de plantas medicinais (SOUSA et al., 1991; MATOS et al., 1998), o presente trabalho teve por objetivo efetuar análises físico-químicas em folhas de dez amostras de reconhecida ação terapêutica freqüentemente utilizadas na medicina popular da Região Nordestina brasileira: Alecrim-pimenta (Lippia sidoides Cham.), Alfavaca (Ocimum gratissimum L.), Cajá-umbu (Spondias aff. tuberosa), Eucalipto (Eucalyptus tereticornis Smith), Goiabeira (Psidium guajava L.), Maracujá (Passiflora edulis Sims.), Mostarda (Brassica integrigolia O. E. Schulz), Quebra-pedra (Phyllanthus amorus Schum. Et Thorn.), Sabugueiro (Sambucus australis Cham. \& Schlecht.) e Torém (Cecropia sp.).

\section{MATERIAL E MÉTODOS}

\subsection{COLETA DAS AMOSTRAS}

As amostras analisadas foram coletadas no Horto de Plantas Medicinais do Centro de Ciências da Universidade Federal do Ceará. As folhas das plantas foram lavadas em água corrente e desionizada, sendo secas à temperatura ambiente em sala ventilada por aproximadamente $12 \mathrm{~h}$. Em seguida, foram picotadas e submetidas às determinações de umidade, gordura, cinzas totais, sílica e fibra bruta.

\subsection{DETERMINAÇÕES ANALÍTICAS}

Para a determinação da umidade, as amostras foram pesadas e aquecidas em estufa (Fanem) a $105-110^{\circ} \mathrm{C}$ até obtenção de massa constante (precisão de $0,1 \mathrm{mg}$ ) (AOAC, 1992). Na análise de gordura, a amostra previamente dessecada foi submetida à extração com hexano por cerca de 8 horas, passando em seguida por processo de evaporação. O resíduo resultante foi aquecido a $105-110^{\circ} \mathrm{C}$ até obtenção 
de massa constante (precisão de 0,1 mg) (AOAC, 1992). Na amostra dessecada e desengordurada foi analisado o teor de fibra bruta, mediante digestão ácida com $\mathrm{H}_{2} \mathrm{SO}_{4} 1,25 \%$, seguida de digestão alcalina com $\mathrm{NaOH} 1,25 \%$. Após as digestões, o resíduo foi submetido a aquecimento a $105-110^{\circ} \mathrm{C}$ e pesado até massa constante. Posteriormente, esse foi calcinado a $550^{\circ} \mathrm{C}$ até massa constante. Nessa determinação foi utilizado o método de Henneberg, citado por WINTON e WINTON (1958). Para se avaliar a concentração de sílica nas amostras, as cinzas foram tratadas com ácido clorídrico e aquecidas em banho-maria, sendo, posteriormente, adicionadas de água destilada. A fração não-solúvel das cinzas foi retida em papel de filtro quantitativo (faixa preta) e calcinada a $900^{\circ} \mathrm{C}$ durante $6 \mathrm{~h}$, sendo pesada depois de resfriada em dessecador (AOAC, 1992). As análises de todas as amostras foram realizadas em triplicata e efetuadas as médias e desvios-padrão relativos (SAS, 1996).

\section{RESULTADOS E DISCUSSÕES}

Os desvios-padrão relativos variaram de 2 a $8 \%$ nas determinações. Os resultados obtidos referentes às análises de umidade, gordura, cinzas totais, fibra bruta e sílica podem ser visualizados na Tabela 1.

Altos teores de umidade foram encontrados nas amostras (faixa de $62-78 \%$ ), perfazendo teor médio de $69,15 \%$. LEAL et al. (2003) encontraram valores semelhantes para umidade (69,6\%), em Capimcidreira. MORAIS et al. (1995) também encontraram altos teores de umidade, em média de $81,76 \%$, em estudo com cinco plantas medicinais distintas. NOGUEIRA et al., (1996) observaram teores de umidade entre $66,57 \%$ e $91,02 \%$, em trabalho realizado com dez plantas medicinais.

Constatou-se que os teores de cinzas totais e fibra bruta apresentaram pouca variação entre si. Os teores de cinzas (5-10\%) evidenciaram a abundância de elementos minerais das plantas estudadas.

A importância da utilização de fibras na dieta alimentar decorre do crescente número de enfermidades ocasionadas por sua deficiência. Encontrou-se teor relativamente elevado de fibra bruta em todos os 
vegetais estudados, mesmo quando comparados com vegetais ricos em fibra (FRANCO, 1998), com destaque para Quebra-pedra e Torém $(15,52$ e $17,75 \%$, respectivamente). Com base nos teores de fibra listados em tabelas para alimentos (FRANCO, 1998) pode-se sugerir estudos para utilização desses dois vegetais como fonte de fibra na dieta alimentar.

\section{TABELA 1 - TEORES DE SÍLICA, UMIDADE, CINZAS TOTAIS, GORDURA E FIBRA BRUTA (\%) ENCONTRADOS NAS AMOSTRAS}

\begin{tabular}{|c|c|c|c|c|c|}
\hline \multirow[t]{2}{*}{ Plantas } & \multicolumn{5}{|c|}{ Teores (\%) } \\
\hline & Umidade & Gordura & $\begin{array}{l}\text { Cinzas } \\
\text { Totais }\end{array}$ & $\begin{array}{l}\text { Fibra } \\
\text { Bruta }\end{array}$ & S lica \\
\hline $\begin{array}{l}\text { Alecrim- } \\
\text { pimenta }\end{array}$ & $63,58-1,45$ & $1,04-0,07$ & $8,97-0,44$ & $8,39-0,38$ & $0,65-0,05$ \\
\hline Alfavaca & $75,47-1,52$ & $1,44-0,08$ & $10,75-0,55$ & $10,34-0,45$ & $1,14-0,09$ \\
\hline CajÆumbu & $70,01-1,39$ & $3,44-0,23$ & $8,40-0,40$ & $10,05-0,43$ & $0,70-0,06$ \\
\hline Eucalipto & $62,58-1,29$ & $2,33-0,17$ & $7,88-0,36$ & $12,89-0,59$ & $0,10-0,01$ \\
\hline Goiabeira & $63,50-1,22$ & $1,09-0,07$ & $5,71-0,32$ & $11,10-0,51$ & $0,49-0,04$ \\
\hline Maracuj $Æ$ & $78,40-1,44$ & $8,19-0,47$ & $10,23-0,52$ & $8,09-0,34$ & $0,88-0,07$ \\
\hline Mostarda & $66,90-1,20$ & $2,42-0,20$ & $6,86-0,54$ & $10,99-0,44$ & $0,49-0,04$ \\
\hline $\begin{array}{l}\text { Quebra- } \\
\text { pedra }\end{array}$ & $70,34-1,55$ & $3,95-0,31$ & $6,44-0,35$ & $17,75-0,75$ & $0,42-0,03$ \\
\hline Sabugueiro & $72,88-1,50$ & $6,26-0,52$ & $9,75-0,50$ & $8,08-0,42$ & $0,41-0,03$ \\
\hline Torøm & $67,87-1,34$ & $1,30-0,09$ & $7,76-0,47$ & $15,52-0,38$ & $1,01-0,09$ \\
\hline
\end{tabular}

Constatou-se sensível dispersão dos resultados (1,04 a 8,19\%) para os teores de gordura, sendo os maiores valores obtidos pelo Maracujá $(8,19 \%)$ e pelo Sabugueiro $(6,26 \%)$. Os menores teores foram verificados para Alecrim-pimenta (1,04\%) e Goiabeira (1,09\%). Tal fato deve ser considerado no uso medicinal desses vegetais, principalmente contra problemas intestinais e estomacais, pois o excesso desse constituinte dificulta o processo de digestão alimentar.

Dentre os dez fitoterápicos estudados, o Maracujá exibiu os maiores 
valores de umidade e de gordura. Quebra-pedra e Torém apresentaram os valores mais elevados para fibra bruta, enquanto a Alfavaca e o Maracujá revelaram maior conteúdo mineral.

\section{CONCLUSÃo}

Para todos os fitoterápicos estudados foram encontrados altos teores de umidade (teor médio de 69,15\%).

Concentrações relativamente elevadas de cinzas totais e baixos valores de sílica indicaram a riqueza mineral das plantas analisadas.

Os resultados encontrados para fibra bruta nos vegetais pesquisados permitem recomendar o estudo da utilização de Quebra-pedra e Torém como fonte de fibra na dieta alimentar.

Dentre os dez fitoterápicos analisados, o Alecrim-pimenta e a Goiabeira destacaram-se pelos baixos teores de gordura, fato considerado positivo para o uso medicinal desses vegetais.

\section{Abstract}

DETERMINATION OF MOISTURE, FIBERS, LIPIDS, ASHES AND SILICA IN MEDICINAL PLANTS

Considering the importance of medicinal plants study, physical-chemical analyses of the leaves were accomplished in ten samples of Lippia sidoides Cham., Ocimum gratissimum L., Spondias aff. tuberosa, Eucalyptus tereticornis Smith, Psidium guajava L., Passiflora edulis Sims., Brassica integrigolia O. E. Schulz, Phyllanthus amorus Schum. Et Thorn., Sambucus australis Cham. \& Schlecht. and Cecropia sp. Amongst all studied vegetables, it was verified that the levels of total ashes and gross fiber showed only a small discrepancy. Only Ocimum gratissimum L. and Passiflora edulis Sims. showed remarkable concentrations of whole ash, which suggests high levels of mineral elements presented in those samples. With regards to gross fiber, it should be pointed out high levels found in Phyllanthus amorus Schum. Et Thorn., and Cecropia sp., further investigations are recommended for the use of such plants as alternative source of fiber in the daily diet. A sensitive variation of the results of fat determination was observed, revealing its lowest content in Lippia sidoides Cham. and Psidium guajava L., which is an important aspect when medicinal use of those vegetables are taken into account.

KEY-WORDS: MEDICINAL PLANTS; FUNCTIONAL FOODS. 


\section{REFERÊNCIAS}

1 AOAC. Association of Official Analytical Chemists. Official methods of analysis of the AOAC international. $12^{\text {th }}$ ed. Washington, $1992.1115 \mathrm{p}$.

2 BROSSE, J. La magie des plantes. Paris: Albin Michel, 1990.

3 DI STASI, L.C. Plantas medicinais: arte e ciência, um guia de estudo interdisciplinar. São Paulo: Editora da Universidade Estadual Paulista, 1996. $230 \mathrm{p}$.

4 FRANCO, F. Tabela de composição de alimentos. 9. ed. São Paulo: Atheneu, 1998. 307 p.

5 HARPER, H.A.; RODWELL, V.W.; MAYES, R.A. Manual químico fisiológico. 5.ed. São Paulo: Atheneu, 1982. 736 p.

6 HASLER, C.M. Functional foods: their role in disease prevention and health promotion. Food Technology, Chicago, v. 52, n. 11, p. 63-68, 1998.

7 LEAL, T.C.A.B.; FREITAS, S.P.; SILVA, J.F.; CARVALHO, A.J.C. Produção de biomassa e óleo essencial em plantas de capim cidreira [Cymbopogon citratus (D.C.) Stapf.] em diferentes idades. Revista Brasileira de Plantas Medicinais, Botucatu, v. 5, n. 2, p. 61-64, abril 2003.

8 MARTINS, E.R.; SANTOS, R.H.S. Plantas medicinais: uma alternativa terapêutica de baixo custo. Viçosa: Conselho de Extensão, UFV, 1995. 34 p. (Informe Técnico, no 73).

9 MATOS, F.J.A. Farmácias vivas. 3. ed. Fortaleza: UFC, 1998. 180 p.

10 MORAIS, N.M.T.; NOGUEIRA, C.M.D.; LOPES, M.F.G.; VASCONCELOS, N.M.S.; SÁ, M.J.H.C. Estudo inorgânico analítico de plantas medicinais. Anais da Associação Brasileira de Química, v. 44, n. 4, p. 14-19, 1995.

11 NOGUEIRA, C.M.D.; MORAIS, N.M.T.; LOPES, M.F.G.; SÁ, M.J.H.C. Análises químicas em plantas medicinais. Revista Brasileira de Farmácia, Rio de Janeiro, v.77, n. 1, p. 5-6, 1996.

12 SAS Institute. Statistics analysis systems (SAS). Cary, NC, 1996.

13 SILVA, D.J. Análise de alimentos (métodos químicos e biológicos). 2. ed. Viçosa: UFV, 1990. 166 p.

14 SOUSA, M.P.; MATOS, M.E.O.; MATOS, F.J.A.; MACHADO, M.I.L.; CRAVEIRO, 
A.A. Constituintes químicos ativos em plantas medicinais. Fortaleza: UFC, 1991. $416 \mathrm{p}$.

15 WHEN is dietary fiber considered a functional food. BioFactors, v. 12, n. 1-4, p. 289-297, 2000.

16 WINTON, A.L.; WINTON, K.B. Analisis de alimentos. 2. ed. Barcelona: Hasa, 1958. $1205 \mathrm{p}$. 